\title{
Mechanical properties of thermally stable cadmium iodoapatite ceramic by reactive spark plasma sintering technique
}

\author{
M. Islam $^{1 *}$, F. Lu ${ }^{1}$ \\ ${ }^{1}$ Louisiana State University, Baton Rouge, LA 70803, USA
}

\begin{abstract}
Apatites based materials have been considered as potential waste forms to immobilize the long-lived radioactive iodine isotope. But the thermal instability and phase decomposition at a higher temperature hamper the waste management process. Spark plasma sintering can be a suitable technique compared to conventional sintering processes due to its rapid heating rate, lower sintering temperature and holding time. In this study, we synthesized a highly dense iodine bearing cadmium iodoapatite ceramic pellets by spark plasma sintering (SPS) technique. We successfully consolidated iodoapatite pellets with $\sim 95.5 \%$ of theoretical density (TD) without any iodine loss and phase decomposition after low temperature sintering at $350{ }^{\circ} \mathrm{C}$ for 15 mins under $100 \mathrm{MPa}$. The theoretical density, micro-hardness, and yield strength of sintered pellets were investigated for different sintering temperatures of $300{ }^{\circ} \mathrm{C}, 350{ }^{\circ} \mathrm{C}$, and $400{ }^{\circ} \mathrm{C}$ and holding time $(15 \mathrm{~min})$ under the pressure of $100 \mathrm{MPa}$. The densified pellets displayed nanocrystalline grain structures of $30-80 \mathrm{~nm}$ size which contributed to enhanced thermal stability and fracture toughness. The X-ray diffraction and EDS analysis also confirms the presence of iodoapatite structures. This advanced fabrication technique using SPS can help to develop thermally durable waste forms and mitigate the challenges to dispose high- level radioactive waste.
\end{abstract}

KEY WORDS: Mechanical properties, Spark plasma sintering, Iodoapatite, Thermally stable

\section{INTRODUCTION}

Long-lived radioactive iodine has serious health and environmental concern due to its exceptional long halflife ( $\sim 15$ million). In order to capture the radioactive iodine produced from nuclear fission reaction and other spent fuel, it is very crucial to densify them into durable ceramic waste forms for the risk-free disposal to environment [1-4]. Apatites are addressed as favorable ceramic waste forms to capture and immobilize the hazardous iodine isotope $\left({ }^{129} \mathrm{I}\right)$ due to their excellent chemical durability, superior radiation stability. Apatites have exceptional channel framework that permits the halogen ions $\left(\mathrm{F}^{-}, \mathrm{Cl}^{-}, \mathrm{Br}^{-}\right)$in the anion site and incorporates them into crystal configuration. It has been investigated experimentally that apatite-based ceramics can accommodate iodine and iodate ions in their X-anion site through the channel framework. But due to their large ionic size (i.e. ionic radii $\left(\mathrm{I}^{-}\right): 1.96 \AA$ ), there is a limitation to successfully synthesize iodine bearing apatites $[1,2,5]$. Consequently, the most synthesized iodoapatites may have limited chemical stability and waste loading. In order to overcome these limitations, a recent analysis by Wang [5] predicted potential cation and anion site candidate materials by using artificial neural network (ANN) method to incorporate iodine into the potential apatite structure.

Several solid-state synthesis routes have been adopted to synthesis various apatite-based waste forms, but due to their long processing temperature, dwell time and slow heating rate, iodine volatilizes $[1,2,4]$. To avoid these major drawbacks, the reactive spark plasma sintering process have been chosen by many researchers, which resulted in a low temperature and rapid heating synthesis with enhanced mechanical properties, chemical durability and radiation stability.

The aim of this study is to synthesize cadmium based ceramic waste form by reactive spark plasma sintering process of stoichiometric $\mathrm{CdO}, \mathrm{CdI}_{2}$, and $\mathrm{V}_{2} \mathrm{O}_{5}$ powder mixture at different sintering temperatures, dwell 
time, and isostatic pressure. The mechanical properties (microhardness, elastic modulus) and fracture surface morphology of these sintered pellets also have been investigated further to explore the performance and structural integrity.

\section{EXPERIMENTAL DETAILS}

In this study, the precursor materials were commercially available micron-sized powders of $\mathrm{CdI}_{2}, \mathrm{CdO}$, and $\mathrm{V}_{2} \mathrm{O}_{5}$ (99.6\% purity; Alfa Aesar, Haverhill, MA). These powders were mixed in a hardened stainless-steel vial in a molar ratio of 1:9:3 at room temperature in a HEBM (SPEX 8000 Mixer Mill, Metuchen, NJ, USA). The powder mixtures were milled for 15 hours at a speed of $1300 \mathrm{rpm}$. The mixtures were separated from balls and dried overnight in a fume hood. Then thermally annealed powder at $200{ }^{\circ} \mathrm{C}$ was loaded into the graphite die and consolidated using Dr. Sinter Lab Jr. SPS system (SPS-211Lx, Fuji Electronic Industrial Inc., Japan) in argon atmosphere. The sintering was done with rapid heating rate of $300{ }^{\circ} \mathrm{C} / \mathrm{min}$ at $300{ }^{\circ} \mathrm{C}$, $350{ }^{\circ} \mathrm{C}$, and $400{ }^{\circ} \mathrm{C}$ under $100 \mathrm{MPa}$ with $15 \mathrm{~min}$ holding time. The density of sintered pellet was measured using Archimedes method. The composition of sintered pellets and powder were characterized by an X-ray diffractometer (PANalytical Empyrean, Westborough, MA) equipped with $\mathrm{Cu} \mathrm{K} \alpha$ radiation ranging from $10^{\circ}$ to $70^{\circ}$ with a $2 \theta$ step of $0.026^{\circ}$ at $45 \mathrm{kV}$ and $40 \mathrm{~mA}$. Field-emission scanning electron microscope FE-SEM (Quanta 3D FEG, FEI company, USA) was used to characterize the microstructure, and surface morphology of the as-milled and sintered fractured surface.

\section{RESULT AND DISCUSSION}

The density of sintered specimen increases with increasing sintering temperatures with same dwell time and pressure. The specimens with iodoapatite structure were presented for the comparison. Detailed sintering parameters, relative density and porosity, are presented in Table 1 . The sintering at $300{ }^{\circ} \mathrm{C}$ was the starting cadmium iodoapatite sample with $85.6 \%$ theoretical density (TD), then the density increases to $95.5 \%$ TD at $350{ }^{\circ} \mathrm{C}$, and the highest density $95.7 \%$ TD was observed at $400{ }^{\circ} \mathrm{C}$. The grain size of all samples at these different temperatures showed similar nanocrystalline structure. Thus, the grain size didn't contribute rather temperature dominated the consolidation process during sintering.

Table 1 Detailed sintering parameters, relative density and porosity.

\begin{tabular}{cccccc}
\hline Specimen & $\begin{array}{c}\text { Sintering } \\
\text { temperature }\left({ }^{\circ} \mathrm{C}\right)\end{array}$ & $\begin{array}{c}\text { Sintering } \\
\text { time (min) }\end{array}$ & $\begin{array}{c}\text { Sintering } \\
\text { Pressure (MPa) }\end{array}$ & $\begin{array}{c}\text { Relative } \\
\text { Density } \\
(\% \mathrm{TD})\end{array}$ & $\begin{array}{c}\text { Porosity } \\
(\%)\end{array}$ \\
\hline $300{ }^{\circ} \mathrm{C} \_15 \_100$ & 300 & 15 & 100 & $85.6 \pm 3.6$ & 14.4 \\
$350{ }^{\circ} \mathrm{C} \_15 \_100$ & 350 & 15 & 100 & $95.5 \pm 2.1$ & 4.5 \\
$400{ }^{\circ} \mathrm{C} \_15 \_100$ & 400 & 15 & 100 & $95.7 \pm 1.2$ & 4.3 \\
\hline
\end{tabular}

The XRD experiment was conducted to characterize the phase composition of the sintered pellets. XRD patterns of the sintered specimens at $300{ }^{\circ} \mathrm{C}, 350{ }^{\circ} \mathrm{C}$, and $400{ }^{\circ} \mathrm{C}$ demonstrated the pure cadmium iodoapatite phase. Fig. 1 shows the XRD pattern after sintering at $350{ }^{\circ} \mathrm{C}$ for $15 \mathrm{~min}$ at the heating rate of $300{ }^{\circ} \mathrm{C} / \mathrm{min}$ under $100 \mathrm{MPa}$ pressure in vacuum environment and confirms the $\mathrm{Cd}_{5}\left(\mathrm{VO}_{4}\right)_{3} \mathrm{I}$ (PDF\# 04-011-3066) [6]. Further increase in temperature can contribute to increase the grain size and begin the phase decomposition by iodine loss. Thus, the controlling of sintering parameters is very crucial to consolidation process to avoid any iodine loss. This characterization result demonstrates the prediction model of Wang [5]. 


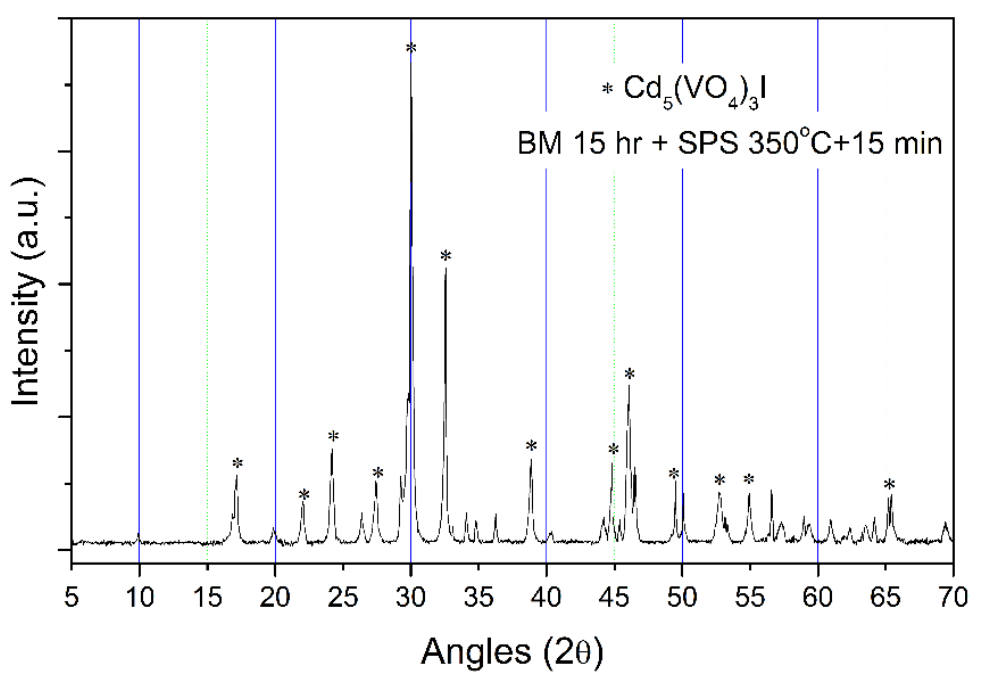

Fig. 1 XRD patterns of cadmium iodoapatite pellets after spark plasma sintering at $350{ }^{\circ} \mathrm{C}$ for $15 \mathrm{~min}$ at the heating rate of $300^{\circ} \mathrm{C} / \mathrm{min}$ under $100 \mathrm{MPa}$ pressure in vacuum environment.

Mechanical properties can be controlled by sintering parameters i.e. temperature, pressure, dwell time etc. and significantly influenced by grain size, density. Hardness and elastic modulus as a function of porosity (\%) of the sintered samples at different temperatures are displayed in Fig. 2. The measured value of these properties of sintered iodoapatite increases with increasing temperature. The sharp increase of hardness and elastic modulus is observed at higher temperatures of $350{ }^{\circ} \mathrm{C}$, and $400{ }^{\circ} \mathrm{C}$ which can be further verified by the SEM fracture morphology. Spark plasma sintered samples have higher density and superior mechanical and corrosion properties as compared to conventional sintering and hot-pressing method $[2,7,8]$. Further increase in temperature decomposes the single-phase structure and deteriorate the mechanical properties by creating minorcracks and secondary materials. The evidence of Hall-Petch equation does not apply to these sintered samples as the porosity hampers the properties and this relation can only be applicable directly to entirely consolidated ( >99) materials when the impact of porosity becomes negligible.
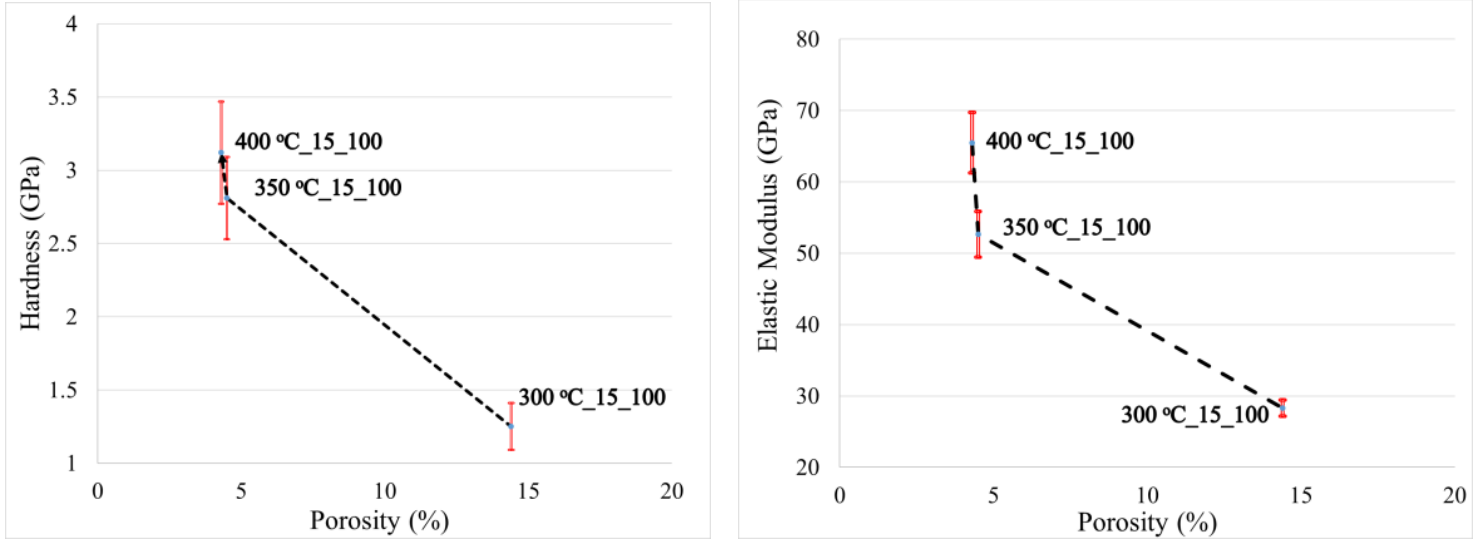

Fig. 2 Mechanical properties (hardness and elastic modulus) of sintered cadmium iodoapatite pellets after spark plasma sintering at $300{ }^{\circ} \mathrm{C}, 350{ }^{\circ} \mathrm{C}$, and $400{ }^{\circ} \mathrm{C}$ as a function of $\%$ porosity

The fracture surface morphology of sintered pellets at different temperatures in the range of $300-400{ }^{\circ} \mathrm{C}$ were investigated. SEM images of as-milled powder samples after 15 hours ball milling and fracture surface of spark plasma sintered sample at $300{ }^{\circ} \mathrm{C}$ are displayed in Fig. 3. Large and irregular shaped particles (200$500 \mathrm{~nm}$ ) were observed in the ball-milled powders. Spherical shaped grains with large size open porosity and small closed porosity agglomerate in the sintered specimen at $300^{\circ} \mathrm{C}$ which is in coherent with the measured low relative density $(\sim 85.6 \% \mathrm{RD})$. The sintered pellets at low temperatures $\left(300-400{ }^{\circ} \mathrm{C}\right)$ demonstrated nanocrystalline finer microstructure which contributed to enhanced thermal stability and fracture toughness. In Fig. 3, the SEM image of fracture surface after sintering at $300{ }^{\circ} \mathrm{C}$ for $15 \mathrm{~min}$ displays finer grains of 
around 30-80 nm size with clearly visible open and close pores. Further increase in temperatures to $350{ }^{\circ} \mathrm{C}$ and $400{ }^{\circ} \mathrm{C}$, the fracture surface shows slight increase of grain size with finer nanocrystalline structure. But the sintering at higher temperature is not recommended for iodoapatite formation specially after $400{ }^{\circ} \mathrm{C}$ there might be the decomposition of single-phase structure due to iodine release and secondary phase formation. The faster heating and cooling rate $\left(30{ }^{\circ} \mathrm{C} / \mathrm{min}\right)$ is assumed for the formation of nanocrystalline grain at lower temperatures $\left(300-400^{\circ} \mathrm{C}\right)$ without any iodine release and phase decomposition which can be verified by the result of Yao et al. [2,7].
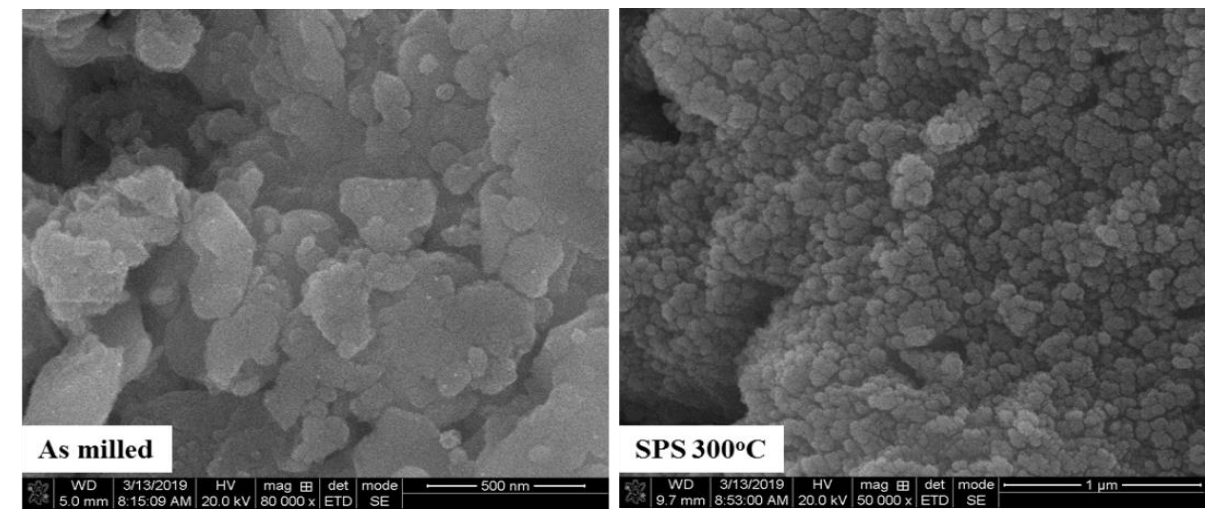

Fig. 3 High magnification SEM images of the (a) as milled powder after $15 \mathrm{~h}$ ball milling, and (b) after sintering at $300{ }^{\circ} \mathrm{C}$.

\section{CONCLUSION}

In this study, we experimented a solid-state reaction sintering technique to consolidate cadmium iodoapatite after ball milling process. We successfully achieved iodine bearing sintered apatite with $95.5 \%$ theoretical density at $350{ }^{\circ} \mathrm{C}$ with fast reactive sintering process. These sintered pellets have higher mechanical properties, better thermal and chemical stability compared to conventionally produced apatites. This new method created a chance to synthesize stable waste forms and disposal of long-lived radioactive iodine.

\section{ACKNOWLEDGMENT}

This work was supported by the NRC Faculty Development Grant. The authors also would like to thank the staff at the Shared Instrumentation Facility (SIF) at Louisiana State University for their assistance during the $\mathrm{XRD}$, and SEM experiments.

\section{REFERENCES}

[1] Lu, F., Yao, T., Xu, J., Wang, J., Scott, S., Dong, Z., Ewing, R. C., Lian, J., "Facile low temperature solid state synthesis of iodoapatite by high-energy ball milling." RSC Advances, 4 (73), pp. 38718-38725 (2014).

[2] Yao, T., Scott, S., Xin, G., Lu, F. and Lian, J., "Dense Iodoapatite ceramics consolidated by low-temperature spark plasma sintering." Journal of the American Ceramic Society, 98(12), pp. 3733-3739 (2015).

[3] Le Gallet, S., Campayo, L., Courtois, E., Hoffmann, S., Grin, Y., Bernard, F. and Bart, F., "Spark plasma sintering of iodinebearing apatite." Journal of Nuclear Materials, 400(3), pp. 251-256 (2010).

[4] Lu, F., Yao, T., Danon, Y., Zhou, J., Ewing, R.C., and Lian, J., "Radiation Stability of Spark-Plasma-Sintered Lead Vanadate Iodoapatite.” Journal of the American Ceramic Society, 98(10), pp. 3361-3366 (2015).

[5] Wang, J., "Incorporation of iodine into apatite structure: a crystal chemistry approach using Artificial Neural Network." Frontiers in Earth Science, 3, p. 20 (2015).

[6] Wilson, A.J.C., Sudarsanan, K., and Young, R.A., "The structures of some cadmiumapatites' Cd5 (MO4) 3X. II. The distributions of the halogen atoms in Cd5 (VO4) 3I, Cd5 (PO4) 3Br, Cd5 (AsO4) 3Br, Cd5 (VO4) 3Br and Cd5 (PO4) 3Cl." Acta Crystallographica Section B: Structural Crystallography and Crystal Chemistry, 33(10), pp. 3142-3154 (1977).

[7] Yao, T., Lu, F., Sun, H., Wang, J., Ewing, R.C. and Lian, J., "Bulk iodoapatite ceramic densified by spark plasma sintering with exceptional thermal stability." Journal of the American Ceramic Society, 97(8), pp. 2409-2412 (2014).

[8] Ettefagh, A. H., Wen, H., Chaichi, A., Islam, M. I., Lu, F., Gartia, M., \& Guo, S. Laser surface modifications of Fe-14Cr ferritic alloy for improved corrosion performance. Surface and Coatings Technology, 125194. (2019) 